\title{
Contribuições para a construção da Nutrição Complementar Integrada*
}

Thaisa Santos Navolar ${ }^{1}$

Charles Dalcanale Tesser ${ }^{2}$

Elaine de Azevedo ${ }^{3}$

NAVOLAR, T.S.; TESSER, C.D.; AZEVEDO, E. Contributions to the construction of Integrative and Complementary Nutrition. Interface - Comunic., Saude, Educ., v.16, n.41, p.515-27, abr./jun. 2012.

The present study approaches the existence of other nutritional rationalities which are distinct from the biomedical one and are often included in the socalled traditional and/or complementary medicine. The hypothesis is that these other eating rationalities are relevant in themselves, deserve to be studied and may contribute to promote Food Security, health education and the enrichment of professional practices in Brazil's Sistema Único de Saúde (SUS National Health System). The goal is to contextualize the interaction of these ideas and practices, and present the initial development of such hypothesis. The biomedical model, which is dominant in the area of nutrition, is revisited, and the need to broaden this perspective is defended. The "medical rationality" category is combined with the notions of food chains and models, in order to perform an initial mapping of the rationalities and food chains under focus.

Keywords: Nutrition. Complementary therapies. Primary care. Food security.
Toma-se por objeto a existência pouco estudada de outras racionalidades nutricionais distintas da biomédica, comumente inseridas nas chamadas práticas e medicinas tradicionais e/ou complementares. A hipótese é a de que essas outras lógicas alimentares são relevantes em si, merecem estudo, e sua tematização pode contribuir para a promoção da segurança alimentar e nutricional, a educação em saúde e o enriquecimento das práticas dos profissionais no Sistema Único de Saúde (SUS). O objetivo é contextualizar a aproximação dessas ideias e práticas e apresentar um primeiro desenvolvimento de tal hipótese. Revisita-se o modelo biomédico, dominante na nutrição, defendendo a necessidade de se ampliar essa perspectiva. Combinam-se a categoria "racionalidade médica" e as noções de modelos e correntes alimentares para um mapeamento preliminar das racionalidades e correntes alimentares em foco.

Palavras-chave: Nutrição. Terapias complementares. Atenção primária à saúde. Segurança alimentar e nutricional.
Artigo inédito Elaborado com base em Navolar (2010), pesquisa

aprovada pelo Comitê de Ética na Pesquisa da Universidade Federal de Santa Catarina.

${ }^{1}$ Programa de PósGraduação em Saúde Pública, Universidade Federal de Santa Catarina (UFSC). Rua Jerônimo Venâncio das Chagas, 55, ap.106. Campeche

Florianópolis, SC, Brasil. 88.063-660.

thaisantosn@gmail.com

${ }^{2}$ Departamento de Saúde Pública, Centro de Ciências da Saúde, UFSC. ${ }^{3}$ Faculdade de Ciências da Saúde, Universidade Federal da Grande Dourados. 


\section{Introdução}

A interface Nutrição-Saúde Coletiva vem ganhando crescente importância na área da saúde, notadamente com o envolvimento de aspectos alimentares e nutricionais em problemas crônicos de alta morbimortalidade. Este artigo insere-se nesta interface com um duplo foco: por um lado, volta-se para a atuação profissional dos nutricionistas no Sistema Único de Saúde (SUS), particularmente os que atuam de alguma forma junto à atenção primária. Por outro lado, relaciona essa atuação com a existência de outras lógicas e, por hipótese, racionalidades nutricionais, distintas da biomédica, nas sociedades e entre os grupos sociais. Algumas dessas racionalidades e práticas, mais ou menos especializadas, são comumente inseridas nas chamadas terapias complementares.

Tal interface, vista nesse duplo foco, é pouco conhecida e explorada tanto no ambiente acadêmico quanto profissional, na Nutrição e na Saúde Coletiva. Para Prado e Bosi (2011), essas duas áreas possuem saberes distintos que se interseccionam na abordagem da Alimentação e Nutrição em Saúde Coletiva, agregando a dietética (derivada da Nutrição) com as abordagens e saberes dos campos disciplinares da Saúde Coletiva.

Em analogia às contribuições do campo das Medicinas Alternativas e Complementares/Medicinas Tradicionais (MAC/MT) (NCCAM, 2010) ou Práticas Integrativas e Complementares (PIC) (Brasil, 2006) para o cuidado em saúde e a promoção da saúde, a hipótese aqui discutida é a de que essas outras lógicas nutricionais ou alimentares são relevantes, podem contribuir na promoção da Segurança Alimentar e Nutricional (Albuquerque, 2009) e auxiliam na ampliação e enriquecimento das práticas profissionais dos nutricionistas. Merecem, portanto, ser reconhecidas, compreendidas e estudadas, constituindo-se em terreno para a construção de um novo campo de saber e prática na Nutrição. O objetivo deste artigo é esboçar uma aproximação e contextualização dessa temática, na interface Nutrição-Saúde Coletiva, caracterizada por diferentes racionalidades e correntes alimentares, que podem constituir o que aqui nomeamos de Nutrição Complementar Integrada ( $\mathrm{NCl}$ ). Ou seja, apresentar um primeiro desenvolvimento da hipótese mencionada acima, de modo sintético e preliminar.

Para atingir esse objetivo, com base em revisão não sistemática e dirigida da literatura atual, é realizada, inicialmente, uma discussão sucinta que revisita alguns aspectos críticos do modelo biomédico hegemônico na área da saúde e, mais especificamente, na Nutrição, abordando características do saber, da prática e da formação dos nutricionistas, relevantes para nosso objetivo, e argumentando pela necessidade de ampliação dessa perspectiva e melhoria da qualidade das práticas profissionais. Isso é articulado a seguir com temas considerados significativos para a contextualização e discussão inicial da hipótese em foco. Nesse sentido, são discutidas sinteticamente as relações entre campos, conceitos e movimentos que podem dialogar com ou, mesmo, atravessar a temática, como: a Segurança Alimentar e Nutricional (SAN), a promoção da saúde (Czeresnia, 2003), a agroecologia (Khatounian, 2001), e a educação em saúde. Contextualizada a hipótese, alguns argumentos são oferecidos para sua fundamentação e primeiro desenvolvimento. Por fim, propõe-se a adoção do uso combinado da categoria 'racionalidade médica' de Luz (2000) e das noções de modelos e correntes alimentares de Azevedo (2006) para um mapeamento das práticas e saberes da $\mathrm{NCl}$, fazendo uma primeira descrição sintética das mesmas.

\section{Medicalização da Nutrição}

O modo de organização social e econômico hegemônico apresenta, a partir do final do século XX,

uma conjuntura mundial com grandes iniquidades e uma mistura de velhos e novos problemas de saúde pública (Luz, 2007). Uma das consequências dessa situação é a grande dependência das pessoas dos bens e serviços de saúde do chamado modelo médico hegemônico (Barros, 2002).

Este processo é conhecido como medicalização social, inicialmente discutido por Foucault (1979) e Illich (1981) com significados e abordagens distintos, porém, em certo sentido, convergentes. Illich (1981) criou o termo "iatrogenia cultural", entendido como a perda do potencial cultural para manejo da maior parte das situações de dor, adoecimento e sofrimento. A medicalização pode ser entendida, portanto, como um processo de apropriação, pela biomedicina e demais profissões da saúde, de cada 
vez mais comportamentos e vivências humanos, caracterizando-os como problemas médicos e/ou para outros profissionais (Tesser, 2010).

Outra repercussão diz respeito ao "higienismo generalizado", termo cunhado por Leccourt (2006) que se refere à rigidez de normas relacionadas ao processo saúde-doença, em especial àquelas que dizem respeito à higiene pessoal e aos alimentos, as quais se especializaram e ganharam certo valor, capaz de transformar o modo de pensar a dieta na modernidade (Carvalho, Luz, Prado, 2011). É neste contexto que as orientações médicas passaram a ter um efeito impactante na vida cotidiana dos indivíduos. A normalização das condutas e estilos de vida nasceu com a Medicina Social, no século XIX, quando as políticas de saúde converteram-se em intervenções sobre a vida privada dos indivíduos (Caponi, 2003). Isso se estendeu à prevenção das doenças, encarada de forma obsessiva e expandida com o apoio da sociedade em geral e da mídia. Tal fenômeno, chamado por Nogueira (2003) de 'higiomania moderna', transforma questões de prevenção em rígidas intervenções e tendências obsessivas introjetadas nos hábitos cotidianos, com culpabilização dos indivíduos, visíveis no âmbito das restrições alimentares. Isso se torna mais importante a partir da constatação de que a alimentação encontra-se direta ou indiretamente envolvida na prevenção de doenças crônicas de alta morbimortalidade.

A ciência da Nutrição está inserida no modelo biologicista, com foco na doença e no risco, fazendo com que parte de suas práticas estejam dedicadas a intervenções de caráter interventivo e restritivo, as quais vêm transformando a educação alimentar em prescrições de suplementos nutricionais e medicamentos, sob a égide dessa higiomania. Beardsworth e Keil (1997) estão entre os autores que enfatizam que o modelo racional e restritivo das intervenções alimentares pode ser entendido como um processo de racionalização e medicalização da dieta.

Para Bosi (2004), os elementos centrais da Nutrição moderna envolvem: uma visão reducionista do ser humano, uma análise parcial e fragmentada da relação com o alimento, a normatização dos sujeitos, a naturalização dos problemas nutricionais, e o enfoque predominantemente curativo, mesmo na prevenção de doenças, já que há, em curso, um progressivo apagamento da distinção prevenção-cura com o manejo dos riscos como se fossem doenças (Starfield et al., 2008).

A prática do nutricionista é fortemente influenciada por estas questões e, ao mesmo tempo, é ativa nelas. Revisar as origens da profissão pode contribuir para se compreender os diferentes significados presentes no conceito de alimentação saudável, um legítimo e polêmico campo de estudo da Nutrição, percebido como uma construção social historicamente permeada pelo risco, com determinantes sociais e políticos (Azevedo, 2008). Na sua construção ressaltam-se as influências do sistema agroalimentar, da indústria alimentícia e do marketing, além da ciência (Azevedo, 2008; Nestle, 2002).

A profissão do nutricionista tem origem nos hospitais, no apoio ao médico na elaboração de dietas, constituindo, assim, uma prática curativa individual (Costa, 1999). A prática clínica do nutricionista tem sido predominantemente centrada no discurso normativo, comum ao discurso médico, com base em regras originadas da perspectiva higienista do século XVIII (Oliveira et al., 2008).

Além disso, apesar de grandes avanços no campo, a formação do nutricionista ainda é deficiente na abordagem de questões políticas, socioeconômicas e culturais, o que repercute na análise crítica a respeito da conjuntura alimentar, no campo da atenção e na inserção do profissional no sistema público de saúde (Ferreira, Magalhães, 2007). Tal formação, com enfoque predominante no alimento e na doença, desarticula a abordagem do contexto social do sujeito com suas crenças e história (Oliveira et al., 2008). Em relação ao campo de representações, valores e crenças envolvidos no ato de se alimentar, destaca-se que as necessidades humanas vão além das nutricionais, e que o nutricionista deve se debruçar sobre as necessidades socioculturais que envolvem tal ato (Garcia, 1997).

A ideia de 'indivíduo normal' foi construída a partir de dados médios da espécie humana e do imaginário social, determinado pelo contexto social, em que a cultura vigente atribuiu a normalidade a padrões idealizados biossociais e culturais, com medidas antropométricas predeterminadas, como a circunferência da cintura, ou a relação do peso com a estatura (Oliveira et al., 2008). Esses autores referem que a ideia de anormalidade enquanto estigma e as representações de desordem ou desvio não são, ainda, objeto de reflexão nos atendimentos nutricionais.

Os aspectos socioculturais da educação nutricional, analisados por Freitas (1997) no período de 1990, trouxeram reflexões necessárias a respeito da orientação nutricional, já que a mesma deveria englobar 
os aspectos sociais, econômicos, culturais e políticos, incluindo, ainda, os aspectos simbólicos do corpo. Foram consideradas duas distintas práticas polares de educação nutricional: por um lado, aquela que leva em consideração os aspectos socioculturais e a história individual/familiar/grupal e, por outro, aquela ahistórica, atemporal, cuja orientação seria verticalizada e uniforme. Em trabalho mais recente, a mesma autora e seus colaboradores asseveram que, na conduta normativa, o paciente tende a receber a dieta como se esta fosse uma 'receita medicamentosa' (Freitas et al., 2008).

O discurso normativo, dissociado de um caráter mais humano das práticas de cuidado e vinculado às prescrições restritivas, reforça o "vigiar e punir" de Foucault (2009). A dieta restritiva não consegue superar a dicotomia entre o prazer de comer e os sentimentos de culpa, e desconsidera outros aspectos simbólicos que envolvem a relação entre o nutricionista e o paciente (Oliveira et al., 2008). Dessa forma, percebe-se a necessidade de se avançar na inserção de diferentes olhares para o cuidado nutricional, seja na prática clínica hospitalar e especializada, seja na atenção primária.

\section{Uma visão ampliada da saúde e da Nutrição}

Existem muitas dimensões que precisam ser consideradas para compor uma visão ampliada da Nutrição contemporânea, especialmente na sua interface com a Saúde Coletiva. Os debates em torno da crise da saúde e a busca da redemocratização do país suscitaram, no Brasil, a mobilização de diversos setores que originaram o movimento da Reforma Sanitária na década de 1970. Seus ideais democratizantes impulsionaram a criação do ideário da Saúde Coletiva e do SUS, com seus princípios de universalidade, equidade e integralidade. No contexto internacional, nessa mesma época, os países do hemisfério norte começam a repensar o seu modelo de saúde. Destaca-se a discussão iniciada no sistema de saúde do Canadá, através do Informe Lalonde (1974), seguida pelo movimento da promoção da saúde, discutido por Czeresnia (2003). No campo da Alimentação e Nutrição, a busca pela intersetorialidade e interdisciplinariedade também direcionava a construção de novos caminhos, "evidenciando a conjugação de esforços desses campos" (Prado, Bosi, 2011, p.15).

A Saúde Coletiva fornece contribuições inegáveis nesse processo, em especial na afirmaç̧ão dos variados determinantes sociais que interferem no direito humano à alimentação adequada. Entretanto, há necessidade de se incluir uma concepção mais sistêmica ou mesmo holística da Nutrição, levando em conta: a relativização dos padrões de normalidade; a amplitude da relação ser humano/alimento; a interface entre a nutrição e a cultura; $e$, ainda, um estreitamento com o meio ambiente e a perspectiva ecológica (Bosi, 2004).

Freitas et al. (2008) propõem uma leitura humanista da ciência da Nutrição, na qual o profissional levaria em conta as representações e interpretações do sujeito de: sua alimentação, seu corpo e sua realidade. Para que isso ocorra, os autores destacam a urgente necessidade de diálogo entre diferentes disciplinas, com o olhar das ciências humanas e da saúde para os profissionais da Nutrição, com vistas a gerar outra interpretação e compreensão da cultura alimentar e suas representações sociais.

Por outro lado, nos últimos trinta anos, aparece um crescente e consistente movimento de revalorização e de procura das PIC no mundo ocidental. Embora constituam um conjunto heterogêneo de saberes e práticas de difícil caracterização, reunidos sob o denominador comum de não pertencerem às práticas sancionadas pela ciência biomédica ou, habitualmente, praticadas pela biomedicina, elas podem ser agrupadas e subdivididas em: sistemas médicos alternativos - homeopatia, medicina ayurvédica, medicina tradicional chinesa (MTC); intervenções mente e corpo - meditações etc.; terapias biológicas fitoterapia, alimentos e suplementos naturais; terapias energéticas - reiki, bioenergia, entre outros; e, por fim, métodos de manipulação corporal e baseados no corpo - massagens, exercícios (NCCAM, 2010).

No Brasil, a institucionalização dessas abordagens teve início a partir do fim da década de 1980, com a criação do SUS, mas evoluíram timidamente no Sistema (Barros, Siegel, Simoni, 2007). Apenas em 2006 foi editada a Política Nacional de Práticas Integrativas e Complementares, incentivando práticas de Medicina Tradicional Chinesa/acupuntura, plantas medicinais e fitoterapia, homeopatia e termalismo, com prioridade para a atenção primária (Brasil, 2006).

Luz (2000) desenvolveu uma abordagem analítica que tem permitido fértil abordagem do universo amplo das PIC, ampliando o entendimento sobre ele e relativizando o paradigma biomédico: a categoria 
Racionalidade Médica - que pode ser entendida como um conjunto integrado de práticas e saberes composto pelas seguintes dimensões: morfologia humana, dinâmica vital, sistema de diagnose, sistema terapêutico e doutrina médica, embasadas numa cosmologia. A partir destas dimensões, foi possível analisar sistemas médicos complexos, como a medicina ayurvédica, a MTC e a homeopatia, além da biomedicina, em suas características, cosmovisões, saberes e técnicas próprias. Isso permitiu a consideração, compreensão e valorização dessas racionalidades, em certa medida independentemente da biociência e suas explicações. Uma abordagem similar pode, por hipótese, fazer o mesmo especificamente no campo da alimentação-nutrição, com a diversificação das lógicas, critérios e valores a serem levados em conta nesse campo - o que implica discussões filosóficas, sociológicas, políticas, epistemológicas e culturais ali envolvidas.

As práticas complementares em Nutrição podem ser classificadas em duas categorias: os "modelos alimentares", que incluem aquelas vinculadas a práticas tradicionais ou derivadas de racionalidades médicas, entre elas a alimentação ayurvédica e a dietoterapia na MTC; e as "correntes alimentares", que abarcam as tendências estruturadas de alimentação que não apresentam um vínculo a alguma religião, sistema tradicional ou racionalidade médica (Azevedo, 2006). A combinação dessas duas abordagens ajuda a esboçar um mapeamento das práticas e racionalidades mais presentes, ainda que em minorias ou em subculturas restritas, cujo conjunto é aqui designado como "Nutrição Complementar Integrada".

O reconhecimento, valorização e estudo da $\mathrm{NCl}$ possibilitam uma futura análise e caracterização pormenorizada de diferentes racionalidades nutricionais no ambiente da Nutrição e Saúde Coletiva, o que implica certa relativização cultural e epistemológica, que permite diversificação das possibilidades de entendimento e de ações nos campos da Nutrição e da Saúde Coletiva. Em outras palavras, o campo emergente da $\mathrm{NCl}$ contribui para a relativização do modelo dominante e da perspectiva energéticoquantitativa da Nutrição, que embasam a noção moderna do que é um alimento saudável. Permitindo contato, estudo e compreensão de outras racionalidades médicas e correntes alimentares, a construção da $\mathrm{NCl}$ pode colaborar na difícil missão de ressignificar as práticas profissionais, facilitando a consideração de valores de várias naturezas (sociais, culturais, ecológicos, nutricionais, espirituais), saberes e cosmovisões distintos, possibilitando um pluralismo enriquecedor das práticas profissionais e alimentares.

Vários campos, conceitos e movimentos na Saúde Coletiva, na promoção da saúde, na educação em saúde e na Nutrição fomentam uma maior abrangência epistemológica, política e cultural da discussão precedente, aumentando, junto com a $\mathrm{NCl}$, o escopo do debate a respeito de uma visão ampliada de saúde e nutrição.

O debate em torno da SAN contribui na medida em que articula diversas estratégias, em virtude do seu caráter essencialmente intersetorial. Alguns são conceitos-chave na compreensão da SAN enquanto ferramenta de promoção da alimentação saudável no SUS, o que se torna elementar para as reflexões acerca da atuação do nutricionista. Considera-se que o entendimento sobre a SAN e sua definição de 'alimento adequado e saudável' pode contribuir para a discussão de outras racionalidades nutricionais e da NCl. A definição de alimentação saudável difundida pelo Ministério da Saúde já engloba as necessidades biológicas e sociais da população, devendo ser acessível, saborosa, variada, colorida e microbiologicamente segura; porém o conceito incorpora, ainda, as questões que envolvem a consideração da cultura alimentar, dos alimentos regionais e das questões afetivas ligadas às práticas alimentares (Brasil, 2007). O Conselho Nacional de Segurança Alimentar e Nutricional (CONSEA) aprofundou a discussão e cunhou o termo alimentação saudável 'e adequada', incorporando questões como a garantia de acesso regular e permanente ao alimento, atendendo, também, "às dimensões de gênero e etnia e às formas de produção ambientalmente sustentáveis, livre de contaminantes físicos, químicos e biológicos e de organismos geneticamente modificados" (CONSEA, 2007, p.20).

A partir desse conceito, para a concretização de políticas de alimentação e Nutrição que considerem essencialmente a promoção da saúde em seu mais amplo sentido, faz-se necessário um olhar para a produção de alimentos socioambientalmente sustentáveis. Isso conduz ao campo de estudos da Agroecologia (Khatounian, 2001), que, entre outros objetivos, se propõe a produzir alimentos sob essa desafiante perspectiva. Embora não possa ser considerada uma racionalidade ou corrente, mas, sim, 
uma atitude alimentar, já inserida em algumas práticas e racionalidades, pode-se afirmar que o consumo de alimentos produzidos sob a ótica da Agroecologia deve ser fomentado em todas as propostas de alimentação saudável.

Além de tais questões, destaca-se a contribuição da educação em saúde, considerando-se, especialmente, a abordagem da educação popular, inspirada nos trabalhos de Paulo Freire, com perspectiva emancipadora (Gomes, Merhy, 2011). A educação nutricional entendida nessa perspectiva se revela como uma ferramenta essencial no manejo de diversas patologias associadas à Nutrição, como, por exemplo, a obesidade; "na medida em que faz do sujeito um co-autor no processo terapêutico, construído a partir de uma relação de trocas, compreensão e respeito à cultura e ao ser humano" (Oliveira et al., 2008, p.188). Essa dimensão educativa demanda atenção urgente no sentido de se promoverem melhorias nas práticas educativas nutricionais no SUS, respeitando os diferentes saberes e contextos, numa construção coletiva de conhecimento e prática.

A atuação dos profissionais de saúde em geral, aí inclusos os nutricionistas, comumente envolve um caráter normativo e, às vezes, prescritivo. No caso dos nutricionistas, tal normatividade pode, muitas vezes, ser atenuada ou, mesmo, evitada. Quando necessária e/ou desejável, a normatividade deve ser trabalhada de forma crítica e cuidadosa. De forma geral, a construção de relações harmoniosas, não autoritárias, contextualizadoras e emancipadoras com os usuários é um desafio para todos os profissionais da saúde. A compreensão e valorização de outros modelos e correntes alimentares e suas características podem facilitar a relativização da visão dominante na Nutrição e ampliar a visão do profissional e seu leque de referências, contribuindo para uma melhor contextualização do cuidado e aproximação das realidades socioculturais.

Essa ampliação pode associar-se a características e práticas pedagógicas que fazem parte de racionalidades não biomédicas, contribuindo, assim, para a promoção da saúde individual e grupal, aumentando o empoderamento comunitário (empowerment) e fomentando uma relação mais dialógica com os sujeitos (Tesser, 2009). Além disso, algumas dessas racionalidades exercem sua normatividade baseada em legitimidades relacionadas a uma sabedoria de vida, com características que envolvem componentes desejáveis de se trazer para o cenário profissional da área de saúde, como: compaixão, diálogo, solidariedade e respeito às individualidades e ao conhecimento esotérico de outras racionalidades, não apreendidos pela razão científica moderna.

Todavia, isso não deve impedir o reconhecimento de que o autoritarismo - hoje, sem dúvida, uma característica do modelo biomédico - merece ser atenuado e relativizado, onde quer que seja encontrado (inclusive, nas outras racionalidades), na direção de uma maior horizontalidade, diálogo, empoderamento e corresponsabilidade refletida e contextualizada. Uma pluralidade cultural, epistemológica e de valores, facilitada pelo reconhecimento, estudo e valorização da $\mathrm{NCl}$, é certamente facilitadora da superação da visão de verdade única, de unidirecionalidade nas práticas educativas e de relacionamento autoritário com os usuários.

Em relação às políticas de saúde, ressalta-se o fortalecimento da Estratégia de Saúde da Família (ESF) e dos Núcleos de Apoio à Saúde da Família (NASF), nos quais a participação de nutricionistas permite a inserção deste profissional na atenção primária. Tal atuação ainda precisa ser melhor definida para superar as perspectivas intervencionistas de mudança de hábitos alimentares. Não obstante, a inserção de nutricionistas pode ter o potencial de promover a integralidade, a perspectiva da promoção da saúde e da intersetorialidade e o fortalecimento da cidadania alimentar (Ferreira, Magalhães, 2007).

\section{A Nutrição Complementar Integrada}

O debate a respeito das práticas integrativas na Nutrição teve início em 2002, momento em que o Conselho Federal de Nutricionistas (CFN) solicitou, às profissionais Deise Lopes Silva e Soraya Terra Coury, de Brasília-DF, que ministram cursos sobre o tema (e que cunharam a expressão Nutrição Complementar Integrada), a elaboração de parecer sobre as seguintes terapias: acupuntura, medicina tradicional chinesa, fitoterapia, oligoterapia, iridologia, florais e homeopatia. Em 2003, o CFN, em parceria com a Associação Brasileira de Nutrição, realizou, em São Paulo, o I Seminário de Terapias Complementares, no qual foram debatidas as seguintes práticas: oligoterapia, fitoterapia, medicina chinesa, florais e iridologia. Um dos 
principais encaminhamentos do Seminário foi a criação de um grupo de trabalho nacional sobre as terapias complementares e grupos de trabalhos regionais (CFN, 2003).

A fitoterapia foi definida como prioritária para ser debatida junto à categoria. No ano de 2005, elaborou-se uma minuta de resolução para a prescrição fitoterápica pelos nutricionistas (Kalluf, 2007). Em 2007, a Resolução 402 do CFN foi aprovada, autorizando a prescrição de fitoterápicos por tais profissionais (CFN, 2007).

Um mapeamento preliminar desse campo é desejável e foi esboçado neste estudo a partir da literatura brasileira na área da nutrição, relativamente bem restrita, já mencionada acima. Uma primeira listagem incluiu: o estudo da fitoterapia/plantas medicinais, a dietoterapia chinesa, a alimentação ayurvédica, a alimentação antroposófica, o vegetarianismo e a alimentação viva. Uma descrição e breve discussão das práticas selecionadas permitiu algum esclarecimento a respeito do que tratam, visando apenas delinear seu conjunto, sintetizado a seguir.

Antes, porém, vale comentar que uma das práticas alimentares inicialmente examinadas foi o aproveitamento integral dos alimentos: o uso de partes comestíveis dos alimentos (como cascas, talos etc.), utilizando-os inteiramente. Alguns autores utilizam o termo "alimentação alternativa" para a definição do uso de alimentos comumente não utilizados para enriquecer a dieta (Santos et al., 2001; Bittencourt, 1998). O incentivo ao aproveitamento integral pode trazer contribuições para diminuir os gastos com alimentação e melhorar a qualidade nutricional do cardápio, além de reduzir o desperdício de alimentos. Apesar destas importantes considerações, esse é um tema controverso na Nutrição (Santos et al., 2001), já que questiona-se focar esta prática para comunidades de baixa renda na tentativa de garantir uma alimentação de melhor qualidade nutricional. Outro aspecto se refere à preocupação com os resíduos de agrotóxicos, presentes, em especial, nas cascas dos alimentos (Stopelli, Magalhães, 2005). Outra crítica vem no sentido dos fatores antinutricionais que afetam a biodisponibilidade dos nutrientes (Bittencourt, 1998; Farfan, 1998). Além destas críticas, os aspectos sociopolíticos devem ser levados em consideração, em especial, em torno da representação social do alimento (Santos, 2001). Assim, neste estudo, o aproveitamento integral dos alimentos, se realizado de forma crítica, poderia ser considerado uma iniciativa de promoção da alimentação saudável, não necessariamente vinculado à $\mathrm{NCl}$.

\section{Alimentação ayurvédica}

A medicina ayurvédica, ou ciência da vida, considerada uma racionalidade médica vitalista por Luz (1996), tem sido desenvolvida há mais de cinco mil anos na Índia, sendo o sistema médico mais antigo conhecido. Nessa medicina a dieta é considerada fundamental para uma vida saudável. Outras práticas, como yoga, exercícios respiratórios, massagens, uso de plantas e meditação, formam um conjunto de ações que promovem a harmonia e saúde. Neste sistema, o equilíbrio do corpo é vinculado a três tipos básicos de energia, denominados doshas - Vata, Pitta, Kapha -, que se referem às características constitucionais, tendo predominância de um ou mais tipos em cada indivíduo. O desequilíbrio destas energias, devido ao excesso ou deficiência de um deles, pode levar o indivíduo a uma doença. A alimentação deve ser personalizada e escolhida de acordo com a constituição individual. Conciliar os seis sabores - doce, salgado, amargo, ácido, adstringente e picante - é essencial para o equilíbrio da dieta na medicina ayurvédica (De Gasperi, Raduns, Guiorzi, 2008).

\section{Alimentação na medicina tradicional chinesa}

A MTC é conhecida mundialmente por suas diversas técnicas de prevenção, promoção e recuperação da saúde, também descrita, por Luz (1996), como uma racionalidade médica vitalista. A acupuntura, o uso de plantas medicinais, as práticas corporais, como o tai chi chuan e o lian gong, e as massagens estão entre as técnicas mais utilizadas. A tradição taoísta, base da cosmologia e da doutrina dessa racionalidade, é centrada no princípio de equilíbrio entre as energias yin e yang, e no conceito de Qi, entendido como a força vital que permeia o universo, manifesta em todos os seres vivos e no ser humano. Além destes princípios, a MTC é baseada no sistema dos cinco elementos ou cinco 
manifestações da energia (água, madeira, fogo, terra, metal), presentes no ser humano, e a partir dos quais todos os fenômenos naturais são classificados. Na alimentação chinesa, a classificação entre yine yang distingue os alimentos de acordo com sua natureza, sendo divididos como: frios, frescos, neutros, mornos ou quentes. Além deste aspecto, a classificação dos cinco elementos atua sobre os alimentos, sendo que cada elemento corresponde a um sabor específico, relacionado a recomendações individuais e a contextos específicos, dependendo do estado de saúde do indivíduo e do ambiente em que vive (Coury, Silva, Azevedo, 2007).

\section{Macrobiótica}

A macrobiótica foi fundada por Ishisuka no Japão, no final do século XIX, a partir da dieta tradicional japonesa. Osawa deu continuidade a seus ensinamentos, trazendo-os para a Europa na década de 1930. Posteriormente, Michio Kushi desenvolveu, nos Estados Unidos, a alimentação macrobiótica padrão, mais utilizada atualmente. Esta corrente alimentar também se baseia na teoria taoísta de equilíbrio entre yin e yang, porém de forma distinta da MTC. De maneira geral, são evitados alimentos crus, frutas, açúcar, excesso de líquidos, leite e carnes; e estimulado o consumo de algas, cereais integrais, especialmente o arroz, legumes cozidos, chás e peixes, e frangos eventualmente, constituindo uma dieta ajustada ao local de origem da Macrobiótica (Azevedo, 2006).

\section{Alimentação antroposófica}

É um recurso terapêutico da medicina antroposófica, cuja base é a Antroposofia, filosofia espiritualista desenvolvida por Rudolf Steiner, na Alemanha, no início do século XX. A medicina é pautada na visão tetramembrada do ser humano: corpo físico, vitalidade, alma e espírito. Na dieta antroposófica, são enfatizadas a origem integral e biodinâmica dos alimentos, sua vitalidade, a diversificação de todos os vegetais, e a prática lactovegetariana, considerando a retirada da carne como uma escolha individual, normalmente envolvida com aspectos de desenvolvimento espiritual (Coury, Silva, Azevedo, 2007).

\section{Fitoterapia/plantas medicinais}

O uso de plantas medicinais é uma constante nas tradições culturais e nas racionalidades médicas mais conhecidas, sendo uma prática terapêutica que atravessa os povos e seus curadores, as racionalidades médicas e os modelos alimentares. Com efeito, apenas as práticas hegemônicas da biomedicina afastaram-se grandemente de seu uso (e, agora, vêm dele se aproximando). Ele é incluído como uma parte da $\mathrm{NCl}$ tanto por ser considerado no seu conjunto como terapia complementar incluída na Política Nacional de Práticas Integrativas e Complementares (Brasil, 2006), quanto por haver regulamentação para sua prescrição pelos nutricionistas brasileiros.

A Resolução (RDC n 242/2008) que regulamenta a prescrição fitoterápica permite, ao nutricionista, a indicação de formas terapêuticas exclusivamente de uso oral. Ressalta-se que existem fitoterápicos de exclusiva prescrição médica (CFN, 2008). O CFN orienta que, para realizar a prescrição, o nutricionista esteja apto para tal por meio de capacitações complementares, já que o tema é ainda pouco abordado na graduação.

O resgate, a utilização e o estudo das plantas medicinais vêm ganhando terreno, tanto no âmbito do SUS, quanto da Nutrição. Parte desse reconhecimento veio da regulamentação da Fitoterapia, instituída pela Política Nacional de Plantas Medicinais e Fitoterápicos, e de ações definidas pelo Programa Nacional de Plantas Medicinais e Fitoterápicos, editado pela Portaria Interministerial 2.926, de 2008 (Brasil, 2009). Com relação ao cuidado, o uso de plantas medicinais na atenção primária pode trazer diversas contribuições, como: a valorização da cultura popular; a geração de emprego e renda através da cadeia produtiva; baixo custo; fácil aplicação e baixo risco; promoção da racionalização do uso dos recursos na saúde e aceitabilidade pela população (Botsaris, 2008). 


\section{Vegetarianismo}

A prática vegetariana, embora presente em muitas culturas tradicionais, vem ganhando adeptos em todos os países. Diversos são os motivos que levam à adoção desta corrente alimentar, dentre eles: os aspectos éticos relacionados à exploração animal; as preocupações com os impactos socioambientais da produção de carne, as preocupações com a saúde, além de aspectos religiosos, filosóficos e culturais.

Existem diferentes tipos de dietas vegetarianas: i) ovolactovegetariana: exclui o consumo de qualquer tipo de carne e inclui ovos, leite e derivados; ii) lactovegetariana: exclui carnes e ovos e permite o consumo de leite e derivados; iii) ovovegetariana: exclui carnes e leite e derivados, mas inclui consumo de ovos; iv) vegana ou vegetariana estrita: não inclui o consumo de nenhum alimento de origem animal, inclusive mel (Couceiro, Slywitch, Lenz, 2008).

Estudos na área demonstram que a dieta vegetariana, quando bem planejada e equilibrada, pode trazer diferentes benefícios à saúde, especialmente se relacionada a um maior consumo de alimentos integrais, de origem ecológica e menor consumo de alimentos industrializados (Coury, Silva, Azevedo, 2007; Teixeira et al., 2006).

O aumento de pesquisas na área tem trazido avanços no que diz respeito às contribuições da dieta vegetariana para a saúde. Apesar destas evidências, o vegetarianismo ainda é considerado um tema controverso na Nutrição, e não é abordado com atenção nos cursos de graduação. Considerando as evidências científicas recentes, a discussão que envolve a SAN e os impactos da pecuária extensiva, e o número crescente de adeptos à prática, é importante aprofundar estudos na área e incluir essa temática nos debates da categoria profissional.

\section{Alimentação viva}

A alimentação viva é uma corrente alimentar centrada na vitalidade dos alimentos, e cujo princípio básico é a valorização dessa vitalidade. Sua difusão inicia-se na década de 1980, nos Estados Unidos, devido aos trabalhos de Ann Wigmore, cuja base vem dos estudos da dieta hipocrática. Os praticantes da alimentação viva excluem, da dieta, alimentos considerados 'desvitalizados': produtos de origem animal, alimentos cozidos e industrializados; consumindo, exclusivamente, frutas e vegetais crus, com ênfase para as sementes germinadas e brotos (Wigmore, 1994).

No Brasil, desde a década de 1990, o Projeto Terrapia, da Escola Nacional de Saúde Pública (Fundação Oswaldo Cruz, Rio de Janeiro), divulga essa proposta, considerando a alimentação viva como um movimento de consciência ecológica e de promoção da saúde (Silva, 2006). O olhar para a vitalidade dos alimentos em oposição à visão estritamente bionutricional pode trazer interessantes contribuições para a Nutrição.

\section{Considerações finais}

As práticas alimentares podem ser compreendidas sob vários enfoques e disciplinas científicas, mas também através de diferentes tradições e racionalidades médicas. O reconhecimento da $\mathrm{NCl}$ como campo de estudo de saberes e práticas pode vir a ser um meio de organizar, estruturar e analisar este universo, ainda pouco valorizado no seu potencial de contribuições à Nutrição, à Saúde Coletiva, à SAN e à educação em saúde. Essa consideração fica reforçada, sobretudo, diante das iniquidades sociais e da crise ambiental ligadas ao sistema agroalimentar dominante, além dos problemas de saúde relacionados à dieta, bem como sua padronização e empobrecimento.

Como mencionado, o universo da $\mathrm{NCl}$ é formado por discussões de modelos alimentares, comumente associados a outras racionalidades médicas, práticas e correntes alimentares tradicionais ou mais recentes. Dentre eles, a alimentação da medicina tradicional chinesa, a macrobiótica, a alimentação ayurvédica e antroposófica são embasadas em racionalidades que podem vir a se tornar novas referências para o campo da Nutrição e para sua atividade profissional, em termos de pesquisas e práticas, conforme sejam progressivamente reconhecidas institucional e socialmente. As demais, 
fitoterapia/plantas medicinais, vegetarianismo e a alimentação viva, bem como o consumo de alimentos ecológicos, podem ser consideradas práticas que revelam uma atitude individual e uma postura social, ambiental e política, inserindo-se em algumas das racionalidades mencionadas, perpassando-as transversalmente de forma parcial e não homogênea.

Considera-se que a discussão da NCl pode trazer contribuições para a Nutrição, para a formação e as práticas dos nutricionistas, em estreita interface com a Saúde Coletiva, articulada às políticas de SAN e de promoção da saúde. Também contribui nesse sentido o fato de as PIC, em geral, estarem relacionadas a uma noção positiva de saúde, serem reconhecidas como mais holísticas e humanizadas (na relação cuidador-doente) e propiciarem uma melhor experiência e vivência dos aprendizados e transformações envolvidos nos processos de adoecimento e cuidado (Levin, Jonas, 2001; Andrade, 2006). Isso ajuda a trazer esses elementos para o debate no exercício profissional e nas diferentes formações da área da saúde. Esse debate sugere a ampliação do reconhecimento das PIC dentro e fora da Saúde Coletiva e da NCI na Nutrição, com novos estudos sobre o tema numa perspectiva de sujeitos sociais que anseiam por um cuidado plural, integral, mais humano e coerente com a proposta de sustentabilidade socioambiental.

Diante do que foi exposto, julga-se defensável a inserção de outras racionalidades médicas e correntes alimentares como objetos de estudo da Nutrição e como futuro possível campo de práticas profissionais. Seu reconhecimento ajuda na percepção e compreensão de outras perspectivas, incluindo, potencialmente, aquelas relativas aos usuários, fortalecendo a proposta de uma abordagem ampliada da saúde, da própria ciência da Nutrição e das práticas alimentares.

\section{Colaboradores}

Os autores trabalharam juntos em todas as etapas de elaboração do artigo.

\section{Referências}

ALBUQUERQUE, M.F.M. A Segurança Alimentar e Nutricional e o uso da abordagem de direitos humanos no desenho das políticas públicas para combater a fome e a pobreza. Rev. Nutr., v.22, n.6, p.895-903, 2009.

ANDRADE, J.T. Medicinas alternativas e complementares: experiência, corporeidade e transformação. Salvador: EDUFBA/EdUECE, 2006.

AZEVEDO, E. Reflexões sobre riscos e o papel da ciência na construção do conceito de alimentação saudável. Rev. Nutr., v.21, n.6, p.717-23, 2008.

Alimentos orgânicos: ampliando os conceitos de saúde humana, ambiental e social. 2.ed. Tubarão: Unisul, 2006.

BARROS, J.A.C. Pensando o processo saúde doença: a que responde o modelo biomédico? Saude Soc., v.11, n.1 p.67-84, 2002.

BARROS, N.F.; SIEGEL, P.; SIMONI, C. Política Nacional de Práticas Integrativas e Complementares no SUS: passos para o pluralismo na saúde. Cad. Saude Publica, v.23, n.12, p.3066-9, 2007.

BEARDSWORTH, A.; KEIL, T. Sociology on the menu. London: Routdedge, 1997.

BITTENCOURT, S.A. Uma alternativa para a política nutricional brasileira? Cad. Saude Publica, v.14, n.3, p.629-36, 1998.

BOSI, M.L.M. A Nutrição na concepção científica moderna: em busca de um novo paradigma. Rev. Nutr., v.7, n.1, p.32-47, 1994. 
BOTSARIS, A. Brasil - plantas medicinais e fitoterápicos: um olhar sobre a atenção à saúde. In: BRASIL. Ministério da Saúde. Secretaria de Atenção à Saúde. Departamento de Atenção Básica. Relatório do $1^{\circ}$ Seminário Internacional de Práticas Integrativas e Complementares em Saúde - PNPIC. Brasília: Ministério da Saúde, 2009. p.170-4. (Série C. Projetos, Programas e Relatórios).

BRASIL. Ministério da Saúde. Secretaria de Atenção à Saúde, Departamento de Atenção Básica. Programa Nacional de Plantas Medicinais e Fitoterápicos. Brasília: Ministério da Saúde, 2009.

- Ministério da Saúde. Secretaria de Atenção à Saúde, Departamento de Atenção Básica. Política Nacional de Práticas Integrativas e Complementares no SUS (PNPIC). Brasília: Ministério da Saúde, 2006. (Série B, Textos Básicos de Saúde).

Ministério da Saúde. Glossário temático de alimentação e Nutrição. Brasília: Ministério da Saúde, 2007. (Série A, Normas e Manuais Técnicos).

CAPONI, S. A saúde como abertura ao risco. In: CZERESNIA, D.; FREITAS, C.M. (Orgs.). Promoção da saúde: conceitos, reflexões, tendências. 2.ed. Rio de Janeiro: Fiocruz, 2003. p.55-77.

CARVALHO, M.S.V.; LUZ, M.T.; PRADO, S.D. Comer, alimentar e nutrir: categorias analíticas instrumentais no campo da pesquisa científica. Cienc. Saude Colet., v.16, n.1, p.155-63, 2011

CONSELHO FEDERAL DE NUTRICIONISTAS - CFN. O nutricionista e a prescrição fitoterápica. Rev. CFN, v.6, n.25, p. 13, 2008.

Resolução 402/2007. Regulamenta a prescrição fitoterápica pelo nutricionista de plantas in natura frescas, ou como droga vegetal, nas suas diferentes formas farmacêuticas, e dá outras providências. Diário Oficial da União, 06 ago. 2007, seção 1. 2003.

. CFN discute as terapias complementares em Nutrição. Rev. CFN, v.10, n.3, p.6,

CONSELHO NACIONAL DE SEGURANÇA ALIMENTAR E NUTRICIONAL - CONSEA. Sistematização das contribuições ao Documento Base. In: CONFERÊNCIA NACIONAL DE SEGURANÇA ALIMENTAR E NUTRICIONAL, 3., 2007, p.3-35. Anais... Fortaleza. Disponível em: http://www4.planalto.gov.br/consea/publicacoes/publiucacoesarquivos/sistematizacao-das-contribuicoes-iii-conferencia-nacional-de-segurancaalimentar-e-nutricional

COSTA, N.M.C. Revisitando os estudos e eventos sobre a formação do nutricionista no Brasil. Rev. Nutr, v.12, n.1, p.5-19, 1999.

COUCEIRO, P.; SLYWITCH, E.; LENZ, F. Padrão alimentar da dieta vegetariana. Einstein, v.3, n.6, p.365-73, 2008.

COURY, S.T.; SILVA, D.L.; AZEVEDO, E. Dietoterapia chinesa, vegetarianismo e nutrição antroposófica. In: MURA, J.D.P.; CHEMIN, S.M.S.S. (Orgs.). Tratado de alimentação, nutrição e dietoterapia. São Paulo: Roca, 2007. p.1017-035.

CZERESNIA, D. (Org.). Promoção da saúde: conceitos, reflexões, tendência. Rio de Janeiro: Fiocruz, 2003.

DE GASPERI, P.; RADUNS, V.; GUIORZI, A.R. A dieta ayurvédica e a consulta de enfermagem: uma proposta de cuidado. Cienc. Saude Colet., v.13, n.2, p.495-506, 2008.

FARFAN, J.A. Alimentação alternativa: análise crítica de uma proposta de intervenção nutricional. Cad. Saude Publica, v.14, n.1, p.205-12, 1998.

FERREIRA, V.A.; MAGALHÃES, R. Nutrição e promoção da saúde: perspectivas atuais. Cad. Saude Publica, v.7, n.23, p.1674-81, 2007. 
FOUCAULT, M. Vigiar e punir: nascimento da prisão. 36.ed. Petrópolis: Vozes, 2009. Microfísica do poder. 18.ed. Rio de Janeiro: Graal, 1979.

FREITAS, M.C.S. Educação nutricional: aspectos socioculturais. Rev. Nutr., v.10, n.1, p.45-9, 1997.

FREITAS, M.C.S. et al. Uma leitura humanista da nutrição. In: FREITAS, M.C.S.; FONTES, G.A.V.; OLIVEIRA, N. (Orgs.). Escritas e narrativas sobre alimentação e cultura. Salvador: EDUFBA, 2008. p.207-15.

GARCIA, R.W.D. Práticas e comportamento alimentar no meio urbano: um estudo no centro da cidade de São Paulo. Cad. Saude Publica, v.13, n.3, p.455-67, 1997.

GOMES, L.B.; MERHY, E.E. Compreendendo a educação popular em saúde: um estudo na literatura brasileira. Cad. Saude Publica, v.27, n.1, p.7-18, 2011.

ILLICH, I. A expropriação da saúde: nêmesis da medicina. 4.ed. São Paulo: Nova Fronteira, 1981.

KALLUF, L.J.H. A realidade da fitoterapia na prática do nutricionista. CRN-3 Notícias, p.36-7, 2007. Disponível em: <http://www.crn3.org.br/atualidades/revistas/arquivos/ edicao 088 artigo.pdf>. Acesso em: 10 fev. 2011.

KHATOUNIAN, C.A. A reconstrução ecológica da agricultura. Botucatu: Agroecológica, 2001.

LECCOURT, D. Normas. In: CAPONI, S.; RUSSO, M. (Orgs.). Estudos de Filosofia e História das Ciências Biomédicas. Florianópolis: Discurso Editorial, 2006. p.293-303.

LEVIN, J.S.; JONAS, W.B. Tratado de medicina complementar e alternativa. São Paulo: Manole, 2001.

LUZ, M.T. Novos saberes e práticas em Saúde Coletiva: estudo sobre racionalidades médicas e atividades corporais. 3.ed. São Paulo: Hucitec, 2007.

Medicina e racionalidades médicas: estudo comparativo da medicina ocidental contemporânea, homeopática, chinesa e ayurvédica. In: CANESQUI, A.M. (Org.). Ciências Sociais e saúde para o ensino médico. São Paulo: Hucitec/Fapesp, 2000. p.181-200.

Racionalidades médicas e terapêuticas alternativas. Rio de Janeiro: IMS/UERJ, 1996. (Série Estudos em Saúde Coletiva, 62).

NAVOLAR, T. S.; A interface entre a nutrição e as práticas integrativas e complementares no SUS. 2010. Dissertação (Mestrado) - Departamento de Saúde Pública, Universidade Federal de Santa Catarina, Florianópolis. 2010.

NCCAM (USA). What is complementary and alternative medicine. 2010. Disponível em: <http://nccam.nih.gov/health/whatiscam/\#1>. Acesso em: 31 out. 2011.

NESTLE, M. Food politics. Berkley: University of California, 2002.

NOGUEIRA, R.P. A saúde pelo avesso. Natal: Seminare, 2003.

OLIVEIRA, J.A.N. et al. Percepção dos obesos sobre o discurso do nutricionista: estudo de caso. In: FREITAS, M.C.S.; FONTES, G.A.V.; OLIVEIRA, N. (Orgs.). Escritas e narrativas sobre alimentação e cultura. Salvador: EDUFBA, 2008. p.175-89.

PRADO, S.D.; BOSI, M.L.M. Alimentação e Nutrição em Saúde Coletiva: constituição, contornos e estatutos. Cienc. Saude Colet., v.16, n.1, p.7-17, 2011.

SANTOS, L.A.S. et al. Uso e percepções da alimentação alternativa no estado da Bahia: um estudo preliminar. Rev. Nutrição, v.14, supl., p.35-40, 2001. 
SILVA, M.L.B.N. Terrapia - criação de ambiente saudável na Atenção Básica. In: CONGRESSO BRASILEIRO DE SAÚDE COLETIVA, 8., e CONGRESSO MUNDIAL DE SAÚDE PÚBLICA, 11., 2006, Rio de Janeiro. Anais... Rio de Janeiro, 2006. 1 cd-rom.

STARFIELD, B. et al. The concept of prevention: a good idea gone astray? J. Epidemiol. Comm. Health, v.62, n.7, p.580-3, 2008.

STOPELLI, I.M.B.S.; MAGALHÃES, C.P. Saúde e segurança alimentar: a questão dos agrotóxicos. Cad. Saude Coletiva, v.10, supl., p.91-100, 2005.

TEIXEIRA, R.C.M.A. et al. Estado nutricional e estilo de vida em vegetarianos e onívoros - Grande Vitória - ES. Rev. Bras. Epidemiol., v.9, n.1, p.131-43, 2006.

TESSER, C.D. (Org.) Medicalização social e atenção à saúde no SUS. São Paulo: Hucitec, 2010.

Práticas complementares, racionalidades médicas e promoção da saúde: contribuições pouco exploradas. Cad. Saude Publica, v.25, n.8, p.1732-42, 2009.

WIGMORE, A. Energia vital: o poder de cura que existe em você. São Paulo: Gaia, 1994.

NAVOLAR, T.S.; TESSER, C.D.; AZEVEDO, E. Contribuiciones para la construcción de la nutrición suplementaria integrada. Interface - Comunic., Saude, Educ., v.16, n.41, p.515-27, abr./jun. 2012.

Tiene por objeto la existencia poco estudiada de otras razones nutricionales que no sean biomédicas, comúnmente insertas en las llamadas prácticas tradicionales o complementarias. La hipótesis es que estas otras lógicas alimentarias merecen un estudio y su tematización puede contribuir en la promoción de la seguridad alimentaria y nutricional, en la educación de la salud y el enriquecimiento de las prácticas profesionales en el Sistema Único de Salud de Brasil. El objetivo es contextuar la aproximación de las prácticas y presentar un desarrollo inicial de tal hipótesis. Revisa el modelo biomédico, dominante en la nutrición, con la defensa de la necesidad de ampliar esta perspectiva. Combina la "racionalidad médica" y los conceptos de cadenas y modelos alimentarios para una asignación preliminar de las racionalidades y cadenas alimentarias en foco.

Palabras clave: Nutrición. Terapias complementarias. Atención primaria a la salud. Seguridad alimentaria. 
